\title{
EL ESPECTRO DE TROTSKY: POLÍTICA Y ESCRITURA EN TRES TRISTES TIGRES DE GUILLERMO CABRERA INFANTE
}

\author{
POR \\ Ana SABAu \\ University of California, Riverside
}

Hacia 1964, después de haber tomado la decisión de dejar Cuba para siempre y tras haber ejercido un cargo diplomático en el extranjero, Guillermo Cabrera Infante ganaría el premio Biblioteca Breve de Seix Barral con una "primera versión" de su conocida novela Tres tristes tigres. El texto, entonces titulado Vista del amanecer en el trópico -que años después, utilizaría para otra obra-, no fue publicado a causa de la resistencia que el régimen franquista manifestó contra la obra y su publicación en España. La primera edición de la novela aparecería sólo tres años más tarde, en 1967, con una serie de cambios destinados a satisfacer el gusto represor de los censores hispanos. Sólo en ediciones posteriores aparecería un recordatorio/reclamo a los recortes que la censura política impuso sobre el texto. ${ }^{1}$ Así, en la página de derechos de la edición de Seix Barral aún se lee la siguiente nota: "Esta edición es íntegra y en ella se han incorporado los cortes que la censura hizo en 1967" (6).

En cierto sentido, Tres tristes tigres inaugura un nuevo episodio de la relación de Cabrera Infante con la literatura; inaugura aquello que la crítica ha visto como una renovación poética, atravesada - entre otras cosas-por un distanciamiento de la política. El mismo Cabrera Infante, en una entrevista que le haría Emir Rodríguez Monegal para Mundo nuevo en 1968, abundaría en su posición al respecto de esta problemática, señalando que los fragmentos de Tres tristes tigres escritos como Vista del amanecer en el trópico en 1964, respondían, primeramente, a una intención política y después a una reflexión estética. Apesadumbrado con la sobre-determinación que el compromiso político habría ejercido sobre su literatura, Cabrera Infante propondría leer en la versión completa de Tres tristes tigres un nuevo origen literario, asociado con una genealogía distinta, más estética que "ética" y radicalmente opuesta al realismo socialista que proliferaba en las letras cubanas del momento:

\footnotetext{
Aunque la censura del texto se rastrea directamente al régimen de Franco, en su artículo "Censor obseso, obsceno" Cabrera Infante también remarca las presiones que la política castrista infligió sobre su trabajo. Es así que me interesa leer Tres tristes tigres, como una respuesta general a una censura que supera el marco de la España franquista.
} 
La pretensión del libro en esa época era un poco sartriana, sartriana no en el sentido de El ser y la nada (1946, ed. 2005) y La náusea (1938, ed. en español 2011), sino en el sentido de ¿Qué es literatura? (1943, ed. en español 1950), de una literatura que quería encontrar zonas de la realidad que eran ejemplares. Una pretensión zdanovista. Inclusive, el libro influido sin duda por la atmósfera de Cuba -a pesar de que en ese momento era yo diplomático en Europa-, era un libro que casi me da pena decirlo resultaba un libro de realismo socialista absoluto [...] Una de las cosas que a mí me parecen logradas en este libro [Tres tristes tigres] es que el libro se movió hacia una zona absolutamente estética, dejó de plantearse problemas éticos de cualquier índole para plantearse todos los problemas estéticos ("Las fuentes de la narración" 49).

A pesar de las aseveraciones de Cabrera Infante sobre su propia obra, me parece que en Tres tristes tigres se hacen legibles una serie de "fantasmas", de espectros, que abren la posibilidad de una lectura política. Sin ignorar las tensiones que Cabrera tendría con el gobierno revolucionario, sobre todo en las décadas de los 60 y 70, lo que aquí sugiero re-ubicaría estos conflictos para abrir su obra a otra perspectiva.

A partir del quiebre literario que la publicación de Tres tristes tigres sugiere, la escritura de Cabrera Infante se corporaliza para dar entrada a un estilo profundamente marcado por la oralidad y el exceso. Lejos de ser obras que pueden ser aprehendidas de forma orgánica, tanto Tres tristes tigres como La Habana para un Infante difunto -quizás las dos obras más importantes del corpus literario de Cabrera- son novelas "Aleph" que incorporan fragmentos de archivos amplios y heterogéneos al tiempo que desarticulan el texto en tanto entidad estable.

La volubilidad de los capítulos y la estructura de ambas novelas se lee como un desafío: escribir sobre Tres tristes tigres implica - si uno no quiere perderse en su inmensidad- elegir un eje de lectura o un episodio que ilustre de forma tangencial las posibilidades del texto. Por eso, he decidido en este ensayo centrarme en el capítulo titulado "La muerte de Trotsky", en donde -desde mi perspectiva-cristalizan varias lecturas posibles sobre el fantasma y la fantasmagoría que son cruciales para abrir el texto a dimensiones poco exploradas que, además, amplían la noción de aquello que define lo político.

Dada la fecha de la publicación de la novela, resulta llamativa la oblicuidad con que Cabrera toca el tema de la Revolución. A lo largo del texto, las referencias directas al régimen castrista y al movimiento revolucionario son escuetas: hay una mención directa a Fidel y otra a la zona de fuga y levantamiento que la sierra constituye dentro del espacio geográfico cubano, pero no mucho más. La Revolución y su joven gobierno aparecen como tangentes del núcleo narrativo de la novela: la vida nocturna cubana, localizada en tan sólo "tres cuadras de La Habana" ("Las fuentes de la narración” 42).

Las noches de cabaret y de boleros son tanto la materia prima de Tres tristes tigres como los dislocadores que desvían la mirada hegemónica que se desprende del contexto histórico cubano. La decisión de centrarse en recuperar los residuos de formas de vida

Revista Iberoamericana, Vol. LXXXI, Núm. 250, Enero-Marzo 2015, 109-123 ISSN 0034-9631 (Impreso)

ISSN 2154-4794 (Electrónico) 
previas al estallido de la Revolución es ya una decisión política que busca provocar un desplazamiento de aquello que en la década de los sesenta era dominante: "Tres tristes tigres demuestra que si algo hay en mi es una enorme nostalgia por estas vidas, por estas formas de vida que han desaparecido" ("Las fuentes de la narración" 49).

Pese a los esfuerzos de Cabrera Infante por esquivarla, la Revolución y sus preceptos, a pesar de ser laterales, habitan el texto y lo minan de forma espectral, invitando a una lectura convexa que emerge de la concavidad, de la huella que aparece desde el comienzo con la advertencia sobre la censura.

El concepto freudiano de disavowal resulta particularmente iluminador para hablar de la tensión entre percepción dominante y percepción desplazada que ocupa el espacio textual de Tres tristes tigres. ${ }^{2}$ En An outline of psycho-analysis (trad. 1989), Freud distingue el concepto de disavowal de las nociones de negación y represión. Éstas últimas, describen mecanismos de defensa particularmente vinculados con la interioridad del sujeto, en tanto que el disavowal sugiere una visión descentrada de la realidad, descrita por la negativa a reconocer de manera completa un hecho que el "mundo exterior" impone sobre el sujeto (Freud 92).

El término disavowal permite arrojar otro tipo de luz sobre ciertos pasajes literarios y los abre a lecturas renovadas. Como lo sugiere Sibylle Fischer en su texto Modernity disavowed (2004), el disavowal no obtura la narración como lo hace el trauma, sino que produce relatos alternativos, a veces espectrales, de lo que se puede leer de manera directa en un texto (37-38). De forma similar, la relación que la novela de Cabrera Infante establece con el contexto de su escritura podría describirse bajo este concepto freudiano. En cierto sentido, Tres tristes tigres establece un vínculo de disavowal con su contexto histórico y lo convierte en uno de los fantasmas centrales del texto. Aquello que ronda de forma diluida por los vericuetos de la novela, no es sólo la Revolución cubana, sino también el lugar que la política ocupa dentro del espacio literario. Este ensayo busca desentrañar el modo en que lo político se hace legible en el texto. La figura del fantasma como concepto para pensar aquello que habita de manera oblicua el texto de Cabrera Infante es algo fundamental para entender cómo el costado político y el costado lingüístico se pliegan en su escritura.

En la entrevista con Rodríguez Monegal, Cabrera Infante tímidamente sugiere el método de la metempsicosis como un posible eje de lectura para su novela (53). Así, decidí ampliar el gesto, para pensar que la transmigración -la actividad y voz de los muertos- se convierte en una figura estructural desde la que es posible estudiar la narrativa de Tres tristes tigres.

2 Utilizo el término disavowal en inglés porque la terminología en español no distingue claramente la diferencia que hay entre la negación y el disavowal. Algunos teóricos utilizan denegación para referirse a este mecanismo freudiano que describe una percepción desplazada.

Revista Iberoamericana, Vol. LXXXI, Núm. 250, Enero-Marzo 2015, 109-123 ISSN 0034-9631 (Impreso)

ISSN 2154-4794 (Electrónico) 
El capítulo "La muerte de Trotsky" es uno de los principales nudos narrativos de la novela desde el cual se puede esbozar una teoría del fantasma en la escritura de Cabrera Infante. La sola mención de Trotsky recupera una zona del archivo marxista y lo pone en juego de forma indirecta (espectral) en el espacio literario. ¿Por qué la presencia de Trotsky en medio del texto? ¿Cuáles son las excavaciones literarias y políticas que trae consigo este episodio para la novela?

Las respuestas a estas preguntas, por supuesto, no son unívocas, sobre todo porque a través de este capítulo se despliega una gran variedad de posibilidades de lecturas sobre la poética (lingüística y política) de Cabrera.

El capítulo se ha leído, principalmente, como parodia del archivo literario cubano. ${ }^{3}$ Enél, Cabrera pone en marcha una máquina plagiaria que imita el estilo de siete escritores fundamentales de la literatura caribeña: José Martí, Lino Novás, José Lezama Lima, Virgilio Piñera, Lydia Cabrera, Alejo Carpentier y Nicolás Guillén. Cada fragmento "fetichiza" las marcas del estilo de estos autores y las replica con la intención de reescribir sietes veces, desde siete perspectivas distintas, el mismo evento: el asesinato de Trotsky por Ramón Mercader en agosto de 1940.

En cierto sentido, el capítulo entero opera como una especie de analogía sobre la traducción o, para usar términos más amplios, como una alegoría sobre la relación que se establece entre el original y la copia. La imitación de las características principales de la escritura de cada autor diluye por completo la posibilidad de pensar en la propiedad (como apropiación) de un estilo literario: lo más propio se convierte en lo más ajeno y en algo reproducible e imitable por otro.

El gesto es contundentemente político: la des-jerarquización de la literatura y la supremacía de la oralidad confluyen cuando la serie de imitaciones se interrumpe y, justamente, lo que se deja leer (¿o escuchar?) es la voz fantasmal de Bustrófedon grabada en un cassette diciendo:

La literatura no tiene más importancia que la conversación y que ninguna de las dos tiene mayor importancia y que ser escritor es lo mismo que ser vendedor de periódicos o periodiquero como decía B. Aunque Bustrófedon dijo bien claro esa y otras veces que la única literatura posible estaba escrita en los muros [...] La otra, decía ahora B., la otra literatura hay que escribirla en el aire, queriendo decir que había que hacerla hablando (Tres tristes tigres 281).

La disolución de la propiedad literaria y estilística se funda en la abolición de la línea que distingue a la copia del original. "La muerte de Trotsky" dinamiza esta desintegración desde varios ángulos. Lo que se lee en él no es meramente una parodia del archivo canónico de la literatura cubana. Se trata de una reflexión profunda sobre

3 Ver, por ejemplo, el artículo "Una novela abierta" de Julio Ortega (92).

Revista Iberoamericana, Vol. LXXXI, Núm. 250, Enero-Marzo 2015, 109-123 ISSN 0034-9631 (Impreso)

ISSN 2154-4794 (Electrónico) 
lo epigonal -casi al modo de Borges- y de su relación con los procesos de traducción. El capítulo abre un espacio para indagar sobre el desplazamiento semántico entre significado y significante (que supone el micro-mecanismo que construye toda la novela), y sugiere un modo desde donde es posible hablar de la noción de fantasma y de su relación con la historia.

Como describiré más adelante, las figuras de Mercader y de Trotsky se convierten en cada uno de los fragmentos plagiados, en tropos literarios que condensan las ideas de Cabrera sobre la lengua, la historia y la política.

El fragmento que imita la escritura de José Martí es el primero del capítulo y habría dos modos de leerlo, ambos vinculados con una forma de problematizar la noción del origen. En primera instancia, la presencia de Martí en relación con la muerte de Trotsky pareciera formar parte de un gesto anacrónico: Martí y Trotsky no coinciden en planos temporales. Pero, ¿cuáles serían los motivos detrás del uso de este anacronismo?

En su libro Scare quotes from Shakespeare (2000), Martin Harries amplía el concepto coloquial de las scare quotes para convertirlas en figuras retóricas que permiten pensar las fantasmagorías que habitan los textos centrales de la teoría social y económica de Keynes y Marx. ${ }^{4}$ En su libro, Harries sostiene que las tragedias de Shakespeare son parte esencial de un archivo de citas que provee a ambos pensadores de un lenguaje espectral que les permite desarrollar aquello que Harries lee a contrapelo como el reencantamiento del mundo moderno a través del fetichismo de las mercancías (1-18).

Las scare quotes se vuelven así citas fantasmales, en tanto que muestran una de las múltiples modalidades en que el pasado ronda, se pierde y reaparece en el presente. Las comillas son la característica central de este concepto: a través de ellas se desnaturaliza lo natural. El entrecomillado aparece como una marca de la apropiación de la voz de un ausente, de un fantasma; pero también como un medio desde el cual es posible generar distancia crítica e irónica sobre la absorción del pasado en el presente.

Para Harries, las scare quotes pueden formar parte de un espectro más amplio de mecanismos retóricos y operaciones epistemológicas entre las que aparece la alegoría histórica. Aunque ambas son formas distintas para hablar de los pliegues que funden temporalidades heterogéneas (anacronismo y analogía histórica), hay algo crucial que las separa: la apertura crítica:

Historical allegory, like anachronism implies a direct mapping of the past on to the present. Unlike anachronism this mapping takes place against an awareness of historical difference. While anachronism naively collapses two different historical periods one

\footnotetext{
4 Me referiré a este concepto en inglés porque no existe una traducción directa al español que conserve la noción de "espanto" que scare quote implica y que es tan importante para este articulo en tanto a la reflexión que establece sobre el fantasma. Las scare quotes son citas entrecomilladas que, a través del uso de estos signos de puntuación, operan con ironía sobre la fuente original.
}

Revista Iberoamericana, Vol. LXXXI, Núm. 250, Enero-Marzo 2015, 109-123 ISSN 0034-9631 (Impreso)

ISSN 2154-4794 (Electrónico) 
into the other, historical allegory willfully violates distinctions without obliterating them (Harries 9).

[La alegoría histórica, como el anacronismo, implica un mapeo directo del pasado dentro del presente. A diferencia de lo que ocurre con el anacronismo, este mapeo se lleva a cabo dentro del marco de una conciencia de diferencia histórica. Mientras que el anacronismo ingenuamente colapsa dos periodos históricos distintos, la alegoría histórica deliberadamente transgrede las distinciones, sin obliterarlas.]

La diferencia entre ambos conceptos sugiere un matiz que es -hasta cierto puntotransportable al texto de Cabrera y a su gesto anacrónico de incorporar a Martí como el primero del archivo que escribe sobre el asesinato de Trotsky. Si, como Harries lo supone, las scare quotes guardan dentro de ellas las semillas de una alegoría histórica, entonces podría leerse "La muerte de Trotsky" en esta clave.

La distancia crítica de estas scare quotes no está dada por el entrecomillado, sino por la imitación: el uso de los dos puntos y el estilo del lenguaje son las huellas, la firma de Martí que ha sido incorporada a la cita: ${ }^{5}$

Cuentan que el desconocido no preguntó dónde se comía o se bebía, sino dónde estaba la casa amurallada y sin quitarse de arriba el polvo del camino, se dirigió a su destinación, que era el último refugio de León Hijo-de-David Bronstein: el viejo epónimo: profeta de una religión herética: mesías y apóstol y hereje en una sola pieza (Tres tristes tigres 245).

La alegoría histórica empieza a delinearse como para-texto del archivo literario cubano. El anacronismo que la funda apunta hacia el intento de disolver la noción de un origen esencial que organiza de modo lineal, cronológico, los eventos históricos.

El modo en que Cabrera Infante concibe y opera sobre el archivo cubano puede pensarse de forma análoga a lo que Derrida escribe sobre el origen protético en Monolingualism of the Other or the Prosthesis of Origin (1998). Para Derrida, el sujeto monolingüista ha sido arrojado a la pura traducción, sin tener, en el comienzo, una lengua propia. Así, Cabrera Infante muestra el archivo cubano como una construcción que desde siempre está ligada a los procesos de traducción, y cuyo ensamblaje es arbitrario.

La aparición de Martí al comienzo del capítulo desnaturaliza su presencia en el canon y evidencia lo protético de las genealogías literarias -en este caso de las relativas a la tradición cubana- que siempre sitúan a Martí en el principio de la literatura "nacional". Martí se filtra entonces como origen sobre el archivo literario, incluso en

5 El título del "escrito" de Martí es "Los hachacitos de rosa" que recuerda al título del poema "Los zapaticos de rosa" que Martí publicó en La edad de oro. El poema utiliza constantemente los dos puntos, como también lo hace Cabrera Infante al imitarlo en este fragmento.

Revista Iberoamericana, Vol. LXXXI, Núm. 250, Enero-Marzo 2015, 109-123 ISSN 0034-9631 (Impreso)

ISSN 2154-4794 (Electrónico) 
aquellos eventos que no le tocaron en vida y es, por antonomasia, el fantasma que se aparece y cuya presencia ronda indiscutiblemente por los pasillos de la literatura de Cuba (¿quizás latinoamericana?).

La entrada de Martí además establece el código que se repetirá en otros fragmentos del capítulo sobre la relación entre Mercader y Trotsky. Más allá de lo que supone la falsa figura del maestro y su discípulo que en ellos se encarna, el tipo de vínculo que los describe en la novela es, un disparador que permite pensar todo el episodio narrativo en términos de traducción; en términos del vínculo entre el original y la copia.

Pronto fueron maestro y discípulo, y mientras el anfitrión noble olvidaba sus cuitas y cautelas y dejaba que el afecto abriera una trocha de fuego de amor hasta su corazón antaño helado de reservas, en el aire hueco y como de negra noche que llevaba el protervo a la izquierda del pecho, se anidaba, siniestro, lento, tenaz el feto de la traición más innoble (Tres tristes tigres 245).

La relación de traición entre Mercader-Trotsky es un tropo que hace visible el conocido adagio italiano "traduttore, tradittore" y, junto con él, el pliegue, el punto de conexión que en la novela de Cabrera se teje entre la política y la lengua. La parodia en nombre de Martí -y luego de Lezama Lima y Guillén- pone en escena la traición política; mientras que el modo de escribir de Cabrera Infante -la apropiación del estilo ajeno, la transportación del evento histórico al plano literario- pone a la traducción en el centro y anuda desde otro ángulo la lengua y la política.

El desliz lingüístico que conduce de la traducción a la traición es uno de los núcleos del "estilo" de Cabrera Infante. El retruécano se convierte en la figura narrativa mínima que, sin embargo, puede leerse de manera extensiva en la textura de Tres tristes tigres. De forma paralela al caso en que el capítulo muestra a Martí y su posición arbitraria y protética dentro del archivo cubano, la diferencia (a veces cuestionada como orgánica o no arbitraria) entre significante y significado, es el mecanismo básico de las exploraciones literarias y políticas de Cabrera Infante.

De algún modo, el retruécano hace visible la experimentación en la escritura. No sólo la relación Trotsky-Mercader puede pensarse como alusión al juego entre traducción/ traición, sino que ellos mismos son tratados por Cabrera como figuras que encarnan el desplazamiento lingüístico y semántico desde el cual el retruécano opera:

1. "Lev Davidovitch Bronstein, el arcediano onomáforo con el pseudonombre de Troztky (sic), murió hoy en esta ciudad" (247).

2. "Pero si Trotsky né Bronstein está muerto (lo que parece en definitiva evidente" (254).

3. "El asesino, Jacobo. Santiago, Yago, Diego. Como se llame. Éste, ese que está ahí. Mollnard, Mercader o como diablos se apellide. Ése. Fue el que me asesinó (261).

Revista Iberoamericana, Vol. LXXXI, Núm. 250, Enero-Marzo 2015, 109-123 ISSN 0034-9631 (Impreso)

ISSN 2154-4794 (Electrónico) 
Lo que hay detrás de ambos personajes es la adopción de un nombre otro: un desliz que en principio es lingüístico pero que no es banal porque pone en juego concepciones complejas sobre repetición y diferencia. El cambio de nombres, como el cambio de letras del retruécano (tr - tr) juega con la yuxtaposición y el desplazamiento entre lo mismo y lo otro; y ésta es una problemática que permea la novela entera: "Trínquenlo, amárrenlo (que es lo mismo) bien" (Tres tristes tigres 262).

Entre Trotsky-Bronstein, Mercader-Mornard, traducción-traición-¿tradición? hay algo que vincula los términos; de modo que no se trata de una diferencia radical, sino de un tipo de continuidad que los enlaza. Ése es justamente el nudo que Cabrera exhibe en su escritura de múltiples formas: desde un nivel concreto en que la marca queda en los significantes, hasta llegar a niveles de mayor abstracción en sus concepciones sobre la historia y la política.

La cuestión sobre la repetición y la diferencia es tanto una terminología para pensar sobre la traducción, al preguntarse por la relación que se abre entre el texto "original" y el texto traducido; como otra forma de cuestionar el modo en que el pasado re-aparece en el presente. Esa huella intangible (¿espectral?) de continuidad entre planos temporales es lo que se evidencia en las diferentes formas de retruécano que funcionan en Tres tristes tigres. Ya en los Cursos de lingüistica general Saussure intuía cierto paralelismo invertido entre lo que denominó la arbitrariedad del signo y la tradición que supone el uso de un lenguaje:

If stability is a characteristic of languages, it is not only because languages are anchored in the community. They are also anchored in time. The two facts are inseparable. Continuity with the past constantly restricts freedom of choice. [...] Ultimately there is a connexion between these two opposing factors: the arbitrary convention which allows free choice, and the passage of time, which fixes that choice. It is because the linguistic sign is arbitrary that it knows no other law than that of tradition, and because it is founded upon tradition that it can be arbitrary (Saussure 74).

[Si la estabilidad es una característica de las lenguas, no lo es solamente porque las lenguas están ancladas en la comunidad; sino porque también están ancladas en el tiempo. Estos dos hechos son inseparables. La continuidad con el pasado restringe la libertad de elección (...) Ultimadamente, hay una conexión entre ambos factores: la arbitrariedad de la convención que permite la libre elección y el paso del tiempo que fija esa elección. Es a causa de la arbitrariedad del signo lingüístico que éste no conoce otra ley que la de la tradición; y es a causa de estar fundado en la tradición que el signo lingüístico puede ser arbitrario.]

El juego entre repetición y diferencia que Cabrera escenifica a través de la escritura, pone en tela de juicio (hasta cierto punto) la teoría de Saussure. Leyendo a Cabrera se produce una sensación de vaivén que oscila entre estar frente a la arbitrariedad absoluta

Revista Iberoamericana, Vol. LXXXI, Núm. 250, Enero-Marzo 2015, 109-123 ISSN 0034-9631 (Impreso)

ISSN 2154-4794 (Electrónico) 
o ante un modo más orgánico de plantearse la conexión, la continuidad entre palabras y formas. El movimiento entre ambas posiciones genera una nebulosidad alrededor del lenguaje que lo barniza con un cierto grado de misticismo lingüístico. La noción que supone una relación orgánica entre el mundo y el lenguaje obstruye el trazo histórico que lo atraviesa. ${ }^{6}$

De forma análoga a lo que ocurre con las mercancías, el retruécano -desde el costado que supone la continuidad entre la palabra y la realidad-produce un grado de fantasmagoría lingüística que es fundamental tener en mente como otra modalidad de lo espectral en el texto.

La política de Tres tristes tigres se lee justamente en estos nudos que revelan una postura concreta en relación con el lenguaje y la historia, y que cristalizan en el capítulo "La muerte de Trotsky". En cierto sentido, los fragmentos que parodian a los siete escritores cubanos, suponen la traducción de un "hecho histórico" a múltiples versiones literarias del mismo. Es en este sentido que se puede hablar también de otro tipo de traducción en el texto, sobre todo si se toma ésta como una especie de traducción intersemiótica (Jakobson 139).

Las múltiples versiones de la muerte de Trotsky se pueden leer como la deconstrucción del acontecimiento histórico como una verdad epistemológica objetiva. La historia como ficción paródica que se escribe desde múltiples perspectivas es algo que está en juego en esta parte de la novela.

Las semillas alegóricas que hay en el anacronismo que supone a Martí escribiendo la muerte de Trotsky, germinan en una visión alternativa de la historia: aquí está la política que emerge del disavowal contextual que marca al libro. Lo que Cabrera delinea en este capítulo es la noción de una historia concebida desde paradigmas opuestos al esquema dialéctico que supondría una concepción "revolucionaria" de la historia. Los planos temporales progresivos se cancelan en el punto en donde el futuro (la muerte de Trotsky) está ya en el pasado (Martí) y viceversa.

La historia en tanto historia aparece en el texto como un fenómeno puramente epigonal: repetición sin salida. El Mornard (Mercader) que el fragmento "escrito" por Virgilio Piñera describe, funciona como otro de los tropos que condensa una crítica a la historia progresiva. Mornard es pura copia; es la aparición y re-aparición del fantasma que amenaza con la repetición incesante de la historia y su violencia:

El asesino no era, como pasa con los epígonos, un original. Él tiene sus antecedentes históricos, claro y la historia de este valle de lágrimas está llena de violencia. Por eso odio tanto a los historiadores, porque detesto con toda mi alma lo violento. Que parece

6 Para profundizar en esta reflexión ver Jacques Derrida Specters of Marx (1993). Cap. 1-3. En particular sus múltiples interpretaciones de la cita de Hamlet: "the time is out of Joint" [el tiempo está fuera de quicio].

Revista Iberoamericana, Vol. LXXXI, Núm. 250, Enero-Marzo 2015, 109-123 ISSN 0034-9631 (Impreso)

ISSN 2154-4794 (Electrónico) 
ser la fuerza motriz de este pequeño mundo en que vivimos. Aunque hay violencias y violencias (Tres tristes tigres 249).

La crítica a las revoluciones como parte de un ciclo histórico en que nada es transformado de forma estructural es el núcleo del fragmento que refiere Piñera. Más adelante, al hablar sobre la Revolución Francesa, el fragmento dice:

Por ejemplo es cierto que la aristocracia francesa estaba en decadencia cuando la exterminaron la Revolución y Danton, Marat y compañía [...] Pero esto no justifica jamás de la vida el quiproquó de la guillotina, porque cortarle la cabeza al prójimo no es el mejor modo de curar el mal aliento (Tres tristes tigres 250).

El modelo histórico que la Revolución esboza no parece representar, para Cabrera, un camino para la transformación estructural de la realidad. Sin embargo, no hay modo de exorcizar su presencia fantasmal; su re-aparición es contundente. Tanto el anacronismo que se traza con la figura de Martí, como la crítica de Piñera a la historia, terminan por diluir la posibilidad de pensar en términos de plano temporal pasado-presente-futuro. La proliferación de fantasmas - que después se anuncia en la obra de teatro de Guillén (otro de los pastiches del capítulo)- es otra de las marcas que complican una visión tradicional del desarrollo histórico: "En menos tiempo de lo que toma pronunciar Stajanoviskii rabótimu politískaya los pasillos del Kremlin se pueblan con decenas, miles, millones (unos cien) de fantasmas políticos" (Tres tristes tigres 280).

Aunque la ironía atraviesa el capítulo entero, haciendo que sea complicado fijar un sentido estable en cada episodio, hay algo de un guiño que prioriza un modelo literario sobre uno histórico. Quizás el desplazamiento de lo político a lo estético que Cabrera define en su entrevista con Rodríguez Monegal puede pensarse en relación con esto y con lo que hasta ahora he leído en "La muerte de Trotsky".

Si regresamos a la propuesta de que el capítulo implica una traducción intersemiótica entre hecho histórico y literatura, el pensamiento de Benjamin sobre la traducción en su ensayo "The Task of the Translator" es particularmente pertinente para ubicar el lugar que la literatura adquiere como alternativa al pensamiento histórico en la novela de Cabrera Infante.

En su ensayo, Benjamin sugiere hablar de traducción utilizando el más allá (después de la vida) como un modo de describir la relación que emerge entre el original y la copia. La traducción es como el fantasma (afterlife) de aquello que se traduce. Lo que es crucial en el pensamiento de Benjamin es el modo en que esta relación fantasmal implica una ida y un regreso entre ambas partes de la traducción: la copia se desprende del original y es habitada por él, a la vez que la copia -como vida más allá de la muerte del texto original- expande las posibilidades del original y así lo transforma: 
Here it can be demonstrated that no translations would be posible if in its ultimate essence it strove for likeness to the original. For in its afterlife-which could not be called that if it were not a transformation and a renewal of something living-the original undergoes a change (Benjamin 77).

[Aquí puede demostrarse que no habría traducción posible si ésta, en su última esencia, buscara la igualdad/similitud con el original. Pues es en el más allá -que no podría llamarse así si no fuera porque implica una transformación y una renovación de algo vivo- que el original se somete a un cambio.]

Cuando la traducción adquiere el poder de transformar aquello que en un sentido le antecede, estamos de nuevo frente a una concepción alternativa de los planos temporales. La traducción pensada casi como fantasma del original la expande en ese más allá que el ser una traducción le asigna. Como el grito de dolor de Trotsky que marca el paso al más allá, y que se escucha en varios de los fragmentos de la serie del capítulo, la traducción-escribe Benjamin-es un eco del original; y ese eco, ese espacio de expansión, le corresponde, en la novela, a la literatura. El espacio literario se concibe como una traducción de la historia; como una zona que sucede al hecho histórico pero que en su acto de escribirla la transforma, la activa.

Algo similar se esboza en el episodio que simula la escritura de Alejo Carpentier. En este fragmento - que pone en marcha un mecanismo de muñecas rusas en el que dentro de la traducción se habla de traducción-, se narra la llegada de Mercader a la casa de Trotsky para asesinarlo. A lo largo de detenidas descripciones de la arquitectura de la casa, se alternan pedazos de lo que supone ser uno de los diálogos entre el discípulo y el maestro. Como un leitmotiv, la narración regresa una y otra vez a una frase dicha por Trotsky, que él mismo traduce mentalmente a otro idioma cada vez que la pronuncia: “"Tengo un santo horror a los diálogos', dijo otra vez el anciano, en ruso ahora, pero pensando cómo sonaría en alemán. Fue esta frase en ritornello lo que le movió a golpear" (Tres tristes tigres 264).

La frase repetida por Trotsky implica siempre una traducción que, desde otro ángulo, marca el colapso de una temporalidad esquemática y lo lleva incluso un paso más allá de lo que sugiere Benjamin. En un sentido, al ser supuestamente escrita por Carpentier, la traducción sucede al evento histórico; pero en otro, dentro de lo que en ella se narra, lo antecede e incluso lo anuncia. El eco de ese horror a los diálogos que tiene Trotsky y que aparece al menos cuatro veces en las primeras páginas de la parodia a Carpentier, dibuja la inversión de la figura del fantasma que regresa: es una profecía de la muerte del maestro. En cierto sentido el episodio sugiere a la traducción como un modo de actualización; como un motor de la historia: la frase que se repite en distintos idiomas ronda el texto y es, según él, lo que impulsa a Mornard a cometer el asesinato. La frase que es traducida incesantemente se esboza como catalizador del suceso.

Revista Iberoamericana, Vol. LXXXI, Núm. 250, Enero-Marzo 2015, $109-123$ ISSN 0034-9631 (Impreso)

ISSN 2154-4794 (Electrónico) 
Regresando al tema del espacio literario como contraste y traducción del espacio histórico, se desprende una reflexión importante sobre el género literario como una mediación entre ambos términos de la relación. "Translation is a mode" [La traducción es una modalidad] (76) escribe Benjamin, y el episodio de Trotsky en la novela apunta a incorporar esta sensibilidad. En el fragmento en que se imita a Piñera se abre una reflexión de la adecuación entre el evento que se escribe (se traduce) y el género que se elige para hacerlo:

En un escenario (y no otra cosa, sea dicho de una vez por todas, fue el chateau fortaleza en que el criminal asesinó a su víctima) realista o realista socialista o social realista aparecían demixtificados y demitificados y demixtimitifcados o demitimixtificados; en uno épico se repartirían los papeles, para decirlo técnicamente, de héroes y villanos. En el de Trotsky, suerte de Agamenón de Rusia-Clitemnestra, serían-son mitificadotes y mitimixtificadores o mixtimitificadores de sus propias personas políticas. Pero el antagonismo sería el mismo, para decirlo con exactitud, en las dos o tres o cuatro concepciones.

$[\ldots]$

Forma artística, contenido ideológico y motivación se funden en una sola y misma cosa: el conflicto planteado. O como diría un cronista policial: el suceso (Tres tristes tigres 252).

Una vez más lo que se apuesta aquí es la relación entre mismidad y diferencia. $\mathrm{Y}$, aunque en la cita anterior el modo no vislumbra una salida a la repetición, lo que Cabrera hace en el capítulo contradice aquello que ha sido escrito como una imitación de Virgilio Piñera. La serie de fragmentos que va de Martí a Nicolás Guillén puede pensarse como un arco compuesto de siete narraciones del mismo evento, cada una utilizando una forma, un género distinto.

El dieciocho brumario de Marx inicia con un episodio crucial para el pensamiento sobre la relación entre repetición y diferencia. Marx cita a Hegel sobre la trágica repetición de la historia, pero deja su marca en la cita en el momento en que introduce algo distinto y añade la farsa:

Hegel remarks somewhere that all facts and personages of great importance in world history occur, as it were, twice. He forgot to add: the first time as tragedy, the second as farce (Marx 15).

[Hegel dice en alguna parte que todos los hechos y peronajes de gran importancia en la historia mundial ocurren, por decirlo así, dos veces. Se le olvidó añadir: la primera vez como tragedia, la segunda como farsa. (Traducción mía)]

Inspirado en la famosa cita, Harries sugiere que en la teoría de Marx esta diferencia que entra al juego de la repetición de la historia se puede leer desde una gradación en el

Revista Iberoamericana, Vol. LXXXI, Núm. 250, Enero-Marzo 2015, 109-123 ISSN 0034-9631 (Impreso)

ISSN 2154-4794 (Electrónico) 
cambio del género literario. El deslizamiento que separa la tragedia de la farsa transforma lo cíclico de la historia y hace que ésta deje de tener un valor real y se convierta en fantasma, en espectáculo, en teatralidad.

Tres tristes tigres traza una transformación de géneros literarios entre el episodio de Martí y el último episodio narrado por Guillén. El arco que se dibuja hace eco del deslizamiento que hay entre lo trágico y lo fársico en el texto de Marx; en la diferencia que se abre entre ambos géneros resuena la concepción de un desplazamiento formal producido en el movimiento de una repetición con diferencia.

La transformación histórica se lee entonces desde un lente literario. La literatura se proyecta en la historia y la provee de un lenguaje desde el cual puede ser pensada. Es así que la diferencia entre un episodio y otro se proyecta como una distinción genérica. De algún modo, los primeros seis fragmentos -desde Martí hasta Carpentier-pueden describirse como traducciones del evento histórico en clave de tragedia. En ellos lo que se re-cuenta es el encuentro entre Trotsky y Mornard, y después el asesinato. En cambio, el fragmento "escrito" por Guillén -después de siete variaciones- marca la repetición del evento como farsa. Si para Marx la historia se repite dos veces, la primera vez como tragedia y la segunda como farsa, para Cabrera Infante, la historia se puede repetir indefinidamente, pero siempre como farsa. En el fragmento de Guillén, Trotsky ya ha sido asesinado y es ya un fantasma que regresa para enfrentar en un diálogo teatral a Mornard y su asesinato. En la farsa el humor llega a su punto culmen, como lo hace en este fragmento, que termina por desintegrarse hacia la voz fantasmal de Bustrófedon en la grabadora:

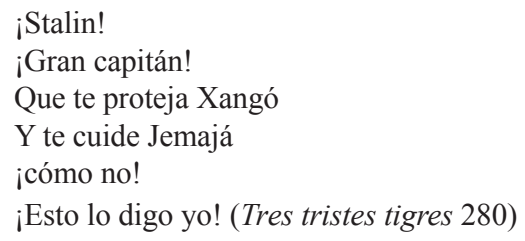

Se podría decir que a través de la re-escritura de las siete versiones de su muerte, Cabrera Infante expande su visión del episodio histórico de la muerte de Trotsky. Como Benjamin lo sugiere: el original perpetúa su vida en la traducción. Así, la muerte del maestro -como lo llama Martí- marca el inicio de otro tipo de vida, la aftertlife benjaminiana que se plasma en la traducción.

"La muerte de Trotsky" figura la concepción de una historia quizás más cercana a aquello que Gilles Deleuze articula en su Repetición y diferencia: la idea del eterno retorno nietzscheano, que no implica la aparición y re-aparición de la copia, sino un desliz, una traducción, una diferencia que, en el caso de Cabrera Infante, entra como marca de la literatura.

Revista Iberoamericana, Vol. LXXXI, Núm. 250, Enero-Marzo 2015, 109-123 ISSN 0034-9631 (Impreso)

ISSN 2154-4794 (Electrónico) 
En este sentido, el desplazamiento hacia lo estético que se delinea en la entrevista con Monegal adquiere un espesor importante para la crítica. La negación de la política es quizás el gesto más político de su giro literario. El disavowal de Tres tristes tigres hacia el contexto histórico de la Revolución cubana emerge como fantasma y hace que desde él sea posible vislumbrar -a través de una teoría de la traducción-, una concepción alternativa a la historia teleológica que se proyecta a través de un uso particular del lenguaje. En la escritura de Cabrera Infante la lengua y la política están íntimamente plegadas y quizás el pliegue que se produce es político en su delinear-desde el fantasmauna visión antagónica a la progresión lineal de la historia.

\section{OBRAS CITADAS}

Benjamin, Walter. "The Task of the Translator." The Translation Studies Reader. Lawrence Venuti, ed. New York: Routledge, 2002. 75-85.

Cabrera Infante, Guillermo. La Habana para un Infante difunto. Barcelona: Seix Barral, 2009.

Tres tristes tigres. Barcelona: Seix Barral, 2005.

"Censor obseso, censor obsceno. Tres tristes tigres acosados, cazados por la censura". Nueva sociedad 100 (1989): 216-22.

"Las fuentes de la narración: diálogo con Emir Rodríguez Monegal". Mundo nuevo 25 (1968): 40-58.

Deleuze, Gilles. Différence et Repétition. Paris: Présses Universitaires de France, 1968. Derrida, Jacques. Monolingualism of the Other or the Prsothesis of Origin. Patrick Mensah, trad. Stanford: Stanford UP, 1998.

Specters of Marx: The State of the Debt, The Work of Mourning \& The New International. Peggy Kamuf, trad. New York: Routledge, 2006.

Fischer, Sibylle. Modernity Disavowed: Haiti and the Cultures of Slavery in the Age of Revolution. Durham: Duke UP, 2004.

Freud, Sigmund. An Outline of Psycho-Analysis. James Strachey, trad. New York: W. W. Norton, 1989.

Harries, Martin. Scare Quotes from Shakespeare: Marx, Keynes, and the Language of Reenchantment. Stanford: Stanford UP, 2000.

Jakobson, Roman. "On Linguistic Aspects of Translation". The Translation Studies

Reader. Lawrence Venuti, ed. New York: Routledge, 2004. 138-143.

Ortega, Julio. "Una novela abierta”. Mundo nuevo 25 (1968): 88-92.

Marx, Karl. The Eighteenth Brumaire of Louis Bonaparte. New York: International Publishers, 2008.

Sartre, Jean Paul. El ser y la nada. Buenos Aires: Losada, 2005. La náusea. Madrid: Alianza, 1938.

¿Qué es la literatura? Buenos Aires: Losada, 1950.

Revista Iberoamericana, Vol. LXXXI, Núm. 250, Enero-Marzo 2015, 109-123 ISSN 0034-9631 (Impreso) ISSN 2154-4794 (Electrónico) 
El eSPeCtro de Trotsky: POLÍtiCA y ESCRITURA EN TRES TRISTES TIGRES ...

Saussure, Ferdinand. Course in General Linguistics. Roy Harris, trad. Chicago: Open Court Publishing Company, 1988. 
